\section{ANTIFUNGAL ACTIVITY OF KEBAR GRASS (BIOPHYTUM PETERSIANUM KLOTSZCH) STEM ETHANOL EXTRACT ON THE GROWTH OF AFLATOXIGENIC ASPERGILLUS FLAVUS IN CORN AND PEANUT-BASED MEDIA}

\author{
Meike Meilan Lisangan, Gino Nemesio Cepeda*, Mathelda
} Kurniaty Roreng

Faculty of Agricultural Technology, Papua University,
Article history

Received

26 February 2019

Received in revised form

30 September 2019

Accepted

2 October 2019

Published online

25 December 2019

*Corresponding author meilan.talakua@gmail.com Manokwari 98324, West Papua, Indonesia

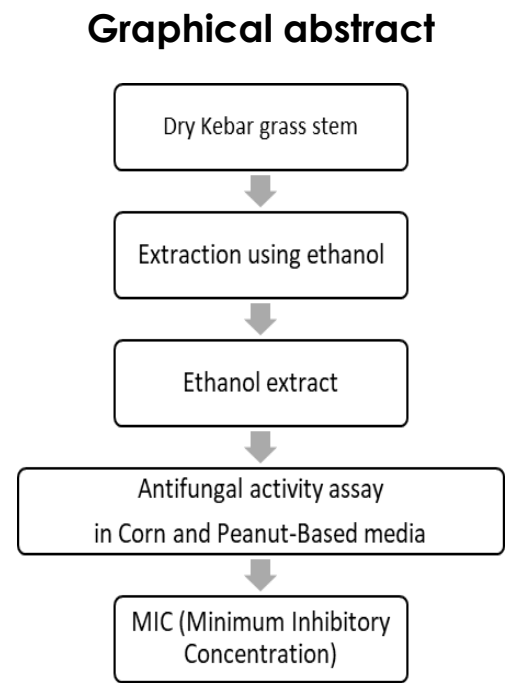

\begin{abstract}
Cereals and legumes are very easily damaged by fungi, including toxigenic fungi species such as Aspergillus flavus which can produce aflatoxins. Various methods have been carried out to reduce aflatoxin contamination in foods, including the use of plant extracts based antimicrobial compounds. One of indigenous herbs in Papua that has potency as natural antimicrobial is Kebar grass (Biophytum petersianum Klotszch). The aims of this study were to investigate the chemical composition and the effect of kebar grass stem ethanol extract on the growth of toxigenic A. flavus. Kebar grass stem ethanol extract at concentrations of $5,10,15$, 20,25 , and $30 \mathrm{mg} \mathrm{mL}^{-1}$ was tested on the growth of A. flavus in two types media i.e. corn based-medium and peanut based-medium. The result showed that kebar grass stem ethanol extract at concentration of $15 \mathrm{mg} \mathrm{ml}^{-1}$ in corn based-medium and peanut based-medium caused $100 \%$ growth inhibition of $A$. flavus. The major compounds in kebar grass stem ethanol extract were: Pyrocatechol, Methylhydrazine hydrochloride, 2-Fluoropropane, Isobutyric acid, 2,6-Dimethoxyphenol. The results obtained from this study suggested that the ethanol extract of the kebar grass stem can be used as a natural antifungal agent to inhibit the growth of aflatoxigenic $A$. flavus.
\end{abstract}

Keywords: Antifungal activity, aflatoxigenic Aspergillus flavus, Biophytum petersianum Klotzsch, corn based-medium, peanut based-medium

(c) 2020 Penerbit UTM Press. All rights reserved

\subsection{INTRODUCTION}

Presence of some fungal in foodstuff and cerealia during storage can cause foodstuff unsafe for human consumption because of nutritional impairment and mycotoxin production [1, 2]. More than $25 \%$ of the world cereals are contaminated with known mycotoxins and more than 300 fungal metabolites are reported to be toxic to human and animals [3]. Carcinogenicity, genotoxicity, terratogenicity, nephrotoxicity, hepatotoxicity, reproductive disorders and immunosuppression were the main toxic [4].

Currently, to prevent fungal growth the food industry still uses synthetic chemical antifungal. Unfortunately, by increasing the activity of microsomal enzymes, some synthetic preservatives or antifungal can convert some ingested materials into toxic or carcinogens substances [5]. In recent years there has been a considerable force to reduce chemically synthesized additives in consumers foods. 
As a one solution is the uses of plant extracts as natural antimicrobial. Plants are well-known as the rich sources of biologically active compounds. As we known, as part of normal metabolism of growth and development or in response to pathogens attack or stress, most plants can produce secondary metabolites as antimicrobial. In the past decade, the interest on the research topic of antimicrobial of plant extracts have been growing. Therefore, for the discovery of antimicrobial agents from natural sources, one of approach that has been used is based on the evaluation of traditional plant extracts [6]. Kebar grass (Biophytum petersianum Klotzsch) was a member of Oxalidaceae family, native to Kebar District, West Papua, Indonesia [7] but widely distributed in the Mali region too. Mali community uses this plant for treatment of wounds, inflammation, ulcers, malaria, and fever [8]. Papua community, especially in Kebar District, often uses this plant as a fertility drug.

In previous research, we found that the extract from kebar grass leaves had good inhibition against growth of aflatoxigenic fungi [9]. Up to now, the antimicrobial activity and substances of kebar grass stem have not been studied yet.

Corn and peanut were agricultural commodities which susceptible to aflatoxigenic fungal infection. One of the most common species of fungus found on corn and peanut was Aspergillus flavus [10, 11]. This fungi can produce aflatoxin, a toxin which is dangerous for human and animals health, if they eat the product which contaminated of aflatoxin. At low concentrations (not more than 20 ppb), aflatoxin can cause liver and kidney cancer, while in high concentration (20 ppb or more), aflatoxin can cause death. Maximum aflatoxin concentration that was permitted to be consumed according to Food and Drug Administration, USA was no more than $20 \mathrm{ppb}$. Corn (Zea mays L.) other than as a source of carbohydrate, is also an important source of protein in the menu of Indonesian society. The content of nutrients in corn such as carbohydrate, protein, fat, and fiber, were potentially to be used by fungi as growth media. Meanwhile, peanuts (Arachis hypogaea L.) was a plant that was very important in the whole world because of the nutritive and economic value [12]. Aflatoxin contamination in peanuts was a major problem for agriculture in a tropical environment. Peanuts could be attacked by the toxigenic A. flavus before and during harvest, drying process and storage [13].

This research aims to investigate the chemical composition and the effect of kebar grass stem ethanol extract on the growth of aflatoxigenic $A$. flavus in corn and peanut based media.

\subsection{METHODOLOGY}

\section{Chemicals and Media}

Chemical viz. Ethanol for extraction was analytical grade and purchased from JT. Baker, USA. Media for antifungal analyses were PDA (Potato Dextrose Agar, Oxoid), Bacto agar (DifCo), aquadest, peanut, and corn.

\section{Preparation of Stem Extracts}

The plant was collected from Kebar district, Manokwari county, West Papua province. Indonesian Institute of Science (LIPI) confirmed identification of kebar grass. The plant was air dried at a temperature of $18^{\circ} \mathrm{C}$ and milled in a manual mill. Powder of kebar grass stem was extracted using maceration method. The kebar grass powder (200 g) was placed in a glass jar (volume $1000 \mathrm{~mL}$ ), then $800 \mathrm{~mL}$ ethanol was added. Its mixture was macerated for one hour at room temperature (28 $30^{\circ} \mathrm{C}$ ) then stirred in a shaker that combined with sonification for 30 minutes, followed by further maceration for one hour then filtered using Whatman No.1 filter paper. The extraction was conducted three times. The extract was collected and dried using a rotary evaporator to form a thick concentrate. The remaining solvent was removed using nitrogen gas. The yield of extract was calculated as the percentage of extract (mg extract/100 $\mathrm{g}$ kebar grass powder). The extracts was stored at $4^{\circ} \mathrm{C}$ until further use [14].

\section{Preparation of Fungal Conidia}

Fungal conidia were prepared by using a method by Joseph et al. [15] with a slight modification. The fungal isolate of $A$. flavus $\mathrm{BIO} 2236$ was grown in PDA slant at $28{ }^{\circ} \mathrm{C}$ for 5 days and the conidia were harvested by using $10 \mathrm{~mL}$ of sterile distilled water and collected aseptically using a sterile inoculation loop. Conidial suspension was dissolved in Tween 80 (0.5\%) and centrifuged $(2000 \mathrm{xg})$ at $28^{\circ} \mathrm{C}$ for 5 minutes. Conidial concentration was calculated using a

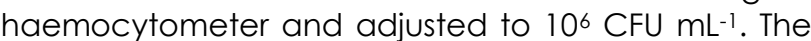
suspension was used to test the effect of kebar grass stem extract in inhibiting the growth of $A$. flavus isolate.

\section{Preparation of Corn Based-media}

Raw corns were sun dried to 13-14\% of moisture content and crushed using a laboratory grinder (Phillips) and filtered out with a mesh size of 70 mesh. Corn agar medium was arranged by adding $5 \mathrm{~g}$ of corn crush into $100 \mathrm{~mL}$ of aquadest, heated for $5 \mathrm{~min}$. After that $2 \mathrm{~g}$ of agar powder was added and liquefied wholly. The corn medium was cooled to 40$45^{\circ} \mathrm{C}$, pH was regulated to 5.6 by added oxalic acid, and $15 \mathrm{~mL}$ solution was moved into $100 \mathrm{~mL}$ conical 
flask and sterilized for 15 min at the temperature of $121^{\circ} \mathrm{C}[15]$.

\section{Preparation of Peanut Based-media}

Raw peanuts were tray dried to $8-9 \%$ of moisture content and shelled manually and milled using a laboratory grinder and filtered out with a mesh size 70 mesh. Peanut agar medium was arranged by adding $5 \mathrm{~g}$ of peanut crush with $100 \mathrm{~mL}$ of aquadest, and heated for $5 \mathrm{~min} .2 \mathrm{~g}$ of agar powder was added and liquefied wholly. The peanut medium was cooled to $40-45^{\circ} \mathrm{C}$, $\mathrm{pH}$ was regulated to 5.6 by added oxalic acid. $15 \mathrm{~mL}$ solution was moved into $100 \mathrm{~mL}$ conical flask and sterilized for $15 \mathrm{~min}$ at the temperature of $121^{\circ} \mathrm{C}[15]$.

Preliminary Phytochemical Screening of Kebar Grass Stem Ethanol Extract

Phytochemical screening of ethanol extract of kebar grass stem was conducted using standard methods to identify the compounds as described by Harborne [16].

\section{Py-GC/MS Analyses of Kebar Grass Stem Ethanol Extract}

Samples of kebar grass stem extract was pyrolyzed using the CDS Pyroprobe 2020is which was directly connected to the gas chromatograph with a Shimadzu GC-MS mass detector (GCMS-QP2010). In each experiment, the sample was injected into a quartz capillary tube that is automatically inserted into the center of a platinum resistor which heats up in an inert atmosphere. The product produced in pyrolysis is quickly removed from the reaction area (quartz capillary surrounded by the resistor) using a helium flow, via a transfer path at the temperature of $280^{\circ} \mathrm{C}$ until it is entered into a gas chromatograph equipped with a mass spectrometry detector for analysis. Pyrolysis temperature was $400{ }^{\circ} \mathrm{C}$. GC analysis was conducted using a Rtx-5MS fused silica capillary column (60 $\mathrm{m} \times 0.25 \quad \mathrm{~mm} \times 0.25 \mu \mathrm{m})$. Temperature of column was $50-280^{\circ} \mathrm{C}$. Helium was used as a carrier gas at a constant pressure of 100 $\mathrm{kPa}$. Identification of different compounds obtained in this analysis was performed using the Wiley 7 mass spectral library [17].

\section{Antifungal Assays}

Kebar grass stem extract effects on mycelial growth of A. flavus isolate was conducted using Tian et al. method [18]. The concentrations of kebar grass extract added to corn and peanut based-media were $5,10,15,20,25$, and $30 \mathrm{mg} \mathrm{mL}^{-1}$. Ten milliliters of each test media containing each extract concentration was poured into a Petri dish $19 \mathrm{~cm}$ in diameter) and left out until it was solidified. Five microliters of conidial suspension of each A. flavus isolate was inoculated on the surface of each test media, and incubated at $28{ }^{\circ} \mathrm{C}$ for 10 days. The diameter of colony (in millimeter) was observed every 24 hours. As negative control, we used fungal cultured in food model media without kebar grass extract. For each treatment combination, we used two replicates including control. The growth inhibition percentage was calculated using following formula:

Growth inhibition $=\frac{d e-d t}{d e} \times 100 \%$.

where $d c=$ diameter of control colony (in $\mathrm{mm}$ )

$d t=$ diameter of fungal colony in treatment set (in $\mathrm{mm}$ )

The concentration of extract that caused $>90 \%$ of growth inhibitory activity was expressed as Minimum Inhibitory Concentration (MIC) and it was used in subsequent test [19].

\section{Statistical Analysis}

Experiments were performed in triplicate and data analyzed are mean \pm SE subjected to one way ANOVA. Means are separated by the Duncan's multiple range test if ANOVA was significant (pb 0.05) (SPSS 12.0; Chicago, IL, USA).

\subsection{RESULTS AND DISCUSSION}

\section{Qualitative Analysis of Phytochemicals}

The result of qualitative phytochemicals analysis of kebar grass stem ethanol extract was shown in Table 1.

Table 1 Phytochemicals of Kebar Grass Stem Ethanol Extract

\begin{tabular}{lc}
\hline Phytochemicals & Ethanol \\
\hline Alkaloids & - \\
Flavonoids & +2 \\
Phenolhydroquinons & +2 \\
Steroids & + \\
Triterpenoids & + \\
Tannins & +2 \\
Saponins & + \\
\hline Note: +++ = Copiously present, ++ = Moderately present, + = Slightly \\
present, - = Absent
\end{tabular}

The result of preliminary phytochemicals analysis indicated the presence of flavonoids, phenolhydroquinons, steroids, triterpenoids, tannins, and saponins, but alkaloid was not detected in ethanol extract. Flavonoids, phenolhydroquinons, steroids, triterpenoids, tannins, and saponins can be extracted in semi-polar to polar solvent. Ethanol was polar solvent, so flavonoids and phenolhydroquinons as polar compounds can be stronger extracted in ethanol [20]. Otherwise, no alkaloid extracted in ethanol due to alkaloid is semi-polar component 
alkaline containing one or more atoms of nitrogen that can only be extracted in a semi-polar solvent [16]. In addition to its functioning as antioxidants [21], flavonoids and phenolhydroquinon also have antimicrobial properties [22, 23].

\section{Py-GC/MS Analyses of Kebar Grass Extract}

A total of 30 components which were identified using pyrolysis/gas chromatography/mass spectrometry (Py/GC/MS) is presented in Table 2. The peak values and structural elucidation of each compound of kebar grass stem ethanol extract is depicted in the Figure 1. The major compounds in kebar grass stem ethanol extract were pyrocatechol (12.50\%), methylhydrazine hydrochloride (7.21\%), 2fluoropropane (12.80\%), isobutyric acid (4.54\%), guaiacol (4.15\%), palmitic acid (3.97\%), 2,6dimethoxyphenol (3.72\%), linoleic acid $(2.89 \%)$, and 4-methyl catechol (1.86\%). Pyrocatechol, guaiacol, 2,6-dimethoxyphenol, and 4-methyl catechol are phenolic compounds. Phenolic group was reported to have broad antimicrobial activity [24]. Meanwhile, isobutyric acid, palmitic acid, linoleic acid are fatty acids that play an important role in live or death of cardiac cells as well as protecting to Parkinson disease [25]. Previous study has been reported various phytochemical groups of fatty acids, amines, phenolics, terpenes, alcohols, hydrocarbons compounds, benzene derivatives, carbohydrate derivatives, steroidal saponin, haloalkane, and sterols from leaves part that extracted by graded solvent of hexane-ethyl acetate-methanol [26].

Table 2 Py/GC/MS Analyses of Kebar Grass Stem Ethanol Extract

\begin{tabular}{rlr}
\hline R.Time & Compounds & Percentage \\
\hline 2.958 & Carbon dioxide (CAS) Dry ice & 4.76 \\
3.257 & Methylhydrazine hydrochloride & 7.21 \\
3.373 & 2-Fluoropropane & 12.80 \\
3.510 & Isobutyric acid & 4.54 \\
3.647 & N-butane-1,1,1-D3 & 28.24 \\
15.560 & I-Limonene & 0.35 \\
17.095 & Guaiacol & 4.15 \\
18.805 & 3,5-Xylenol & 0.46 \\
19.076 & 2-Methoxy-4-methylphenol & 0.53 \\
19.673 & Pyrocatechol & 12.50 \\
20.047 & 1-Phenyl-2-ethylbutane & 0.71 \\
20.535 & p-Ethylguaiacol & 0.98 \\
21.172 & Phenol, 4-ethenyl-2-methoxy- & 0.45 \\
21.297 & 4-Methyl catechol & 1.86 \\
21.530 & 2,6-Dimethoxyphenol & 3.72 \\
21.967 & n-Tetradecane & 0.41 \\
23.203 & Eugenol & 0.68 \\
23.384 & n-Pentadecane & 0.59 \\
24.539 & Nonoic acid & 3.48 \\
24.712 & n-Hexadecane & 0.50 \\
\hline & &
\end{tabular}

\begin{tabular}{clr}
\hline R.Time & Compounds & Percentage \\
\hline 26.088 & Methyl-(2-hydoxy-3-ethoxy-benzyl) & 0.36 \\
& ether & 0.35 \\
26.949 & Myristic acid & 0.68 \\
27.654 & Phytol & 3.97 \\
29.197 & Palmitic acid & 2.89 \\
31.179 & Linoleic acid & 0.76 \\
31.272 & 9,12,15-Octadecatrien-1-ol & 0.66 \\
31.353 & Stearic acid & 0.45 \\
31.515 & n-Docosane & 0.95 \\
43.341 & Squalene & 0.01 \\
& Unknown & 100.00 \\
\hline
\end{tabular}

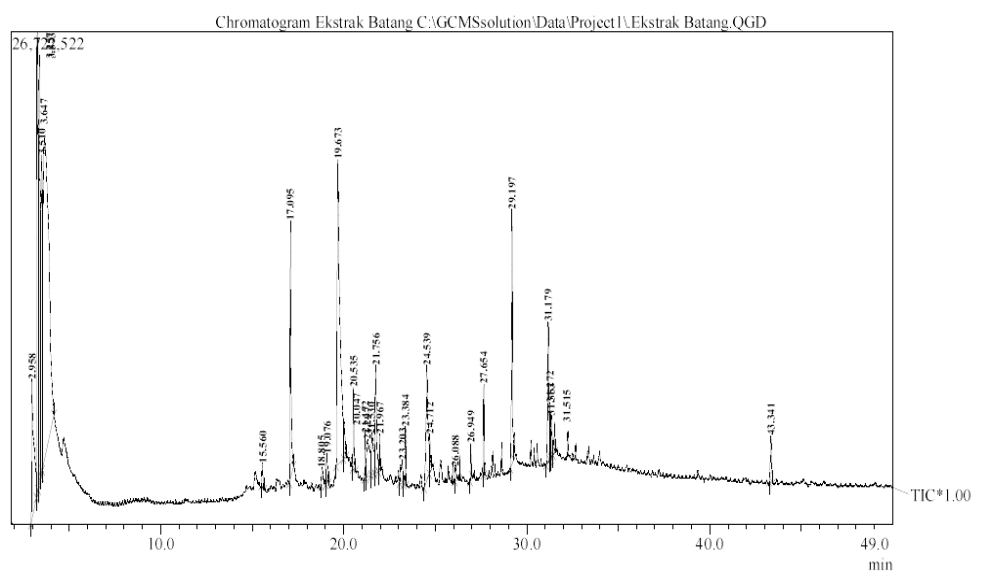

Figure 1 Py/GC/MS of Kebar Grass Stem Ethanol Extract

\section{Antifungal Activity of Kebar Grass Stem Ethanol Extract}

Microbial infestation are adversely affected the shelf life and quality of food. As a key food spoilling fungi, A. flavus can bring down nutritive values of foods. Other than that, A. flavus can producing aflatoxins and makes food containing aflatoxins harmful for human consumption. Usually, food spoilage is the results of interactions of various types microorganisms. Therefore, to provide complete preservation, we need broad-spectrum antimicrobials. Kebar grass stem ethanol extract exhibits a strong fungitoxic effect, so it can be recommended as a good antimicrobial for food preservation.

Antifungal activity of kebar grass stem ethanol extract on corn based-media was shown in Figure 2. Figure 2 showed that there were differences of growth inhibition among the concentration of the extract used, with percentage of growth inhibition varied from 58.9 to $100 \%$. Extract concentration of 5 $\mathrm{mg} \mathrm{mL}^{-1}$ resulted in growth inhibition as much as $58.9 \%$, concentration of $10 \mathrm{mg} \mathrm{mL}^{-1}$ resulted in growth inhibition of $80.6 \%$, and at concentrations of $15-30$ $\mathrm{mg} \mathrm{mL}^{-1}$ growth of $\mathrm{A}$. flavus was completely inhibited. It is known that the higher its concentration the higher the extract produced growth inhibition. This condition is related to the higher activity of bioactive 
components contained in the extract caused by the higher concentration of extract being used. Extract concentration of $15 \mathrm{mg} \mathrm{mL} \mathrm{mL}^{-1}$ resulted in growth inhibition as much as $100 \%$, so it could be concluded that the MIC for corn was $15 \mathrm{mg} \mathrm{mL}^{-1}$.

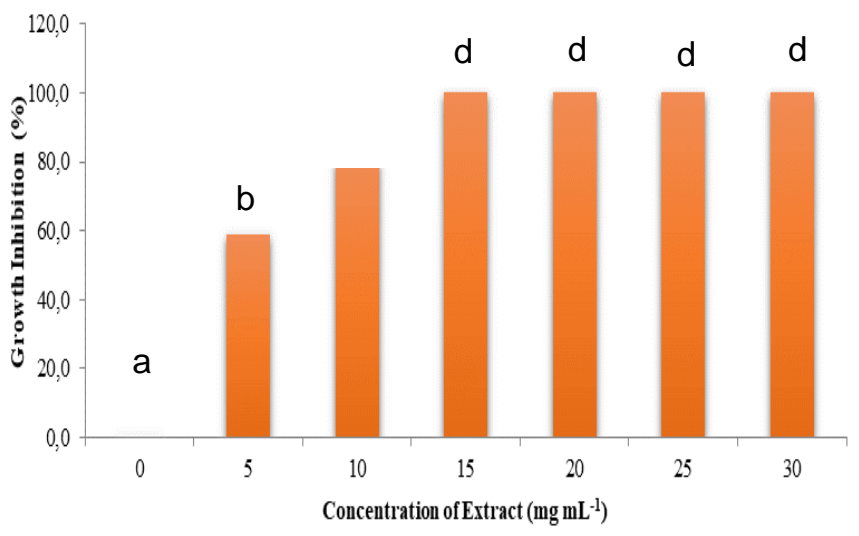

Figure 2 Growth inhibition of kebar grass stem ethanol extract on Aspergillus flavus BIO 2236 in corn based-medium (Values are mean $(n=3) \pm S E$. The means followed by same letter are not significantly different according to ANOVA and Duncan's Multiple Range Tests)

Antifungal activity of kebar grass stem ethanol extract on peanut based-media was shown in Figure 3. Figure 3 showed that there were differences of growth inhibition among the concentration of the extract used, with percentage of growth inhibition varied from 70.7 to $100 \%$. Extract concentration of 5 $\mathrm{mg} \mathrm{mL}^{-1}$ resulted in growth inhibition of $70.7 \%$, a concentration of $10 \mathrm{mg} \mathrm{mL} \mathrm{mL}^{-1}$ resulted in growth inhibition of $85.2 \%$ and at concentrations of $15-30 \mathrm{mg}$ $\mathrm{mL}^{-1}$ growth of $A$. flavus was completely inhibited. As like as corn based media, the higher its concentration the higher the extract produced growth inhibition. This condition was caused by the higher concentration of extract used, the higher the activity of bioactive components contained in the extract. Extract concentration of $15 \mathrm{mg} \mathrm{mL}^{-1}$ resulted in growth inhibition of $100 \%$, so it was concluded that the MIC for peanut based media was $15 \mathrm{mg} \mathrm{mL}^{-1}$.

Growth inhibition of extract between two types of media was different. In peanut based media, the growth inhibition of concentrations of 5 and $10 \mathrm{mg}$ $\mathrm{mL}^{-1}$ were higher than the growth inhibition produced by the same concentration in corn based media. This difference was suspected because of protein and carbohydrate in the form of a monosaccharide, disaccharide or polysaccharide contained nutrients potentially for the growth of A. flavus.

According to Diener and Davis [27], A. flavus was able to grow well in substrates containing enough sucrose, glucose, ribose, xylose and glycerol and protein, both organic and inorganic. This condition is also caused by the use of bacto agar as binder in the making of corn and peanut based media, which is thought to affect moisture content and water activity of corn and peanut media. The water content of maize powder that used as growing medium is $13-14 \%$ while the moisture content of peanuts is $8-9 \%$. The addition of bacto agar medium containing water will increase the water content of corn and peanut media. According to Cuero et al. [28], fungi need water to support their growth. The more humid a conditions of a growing medium, the easier fungi to grow. At temperatures between 25-27 ${ }^{\circ} \mathrm{C}$ and water activity between 0.90-0.98 microbes can grow on materials with a moisture content of 13$18 \%$. It is thought to affect a high percentage of fungi growth inhibition on peanut based media than corn based media.

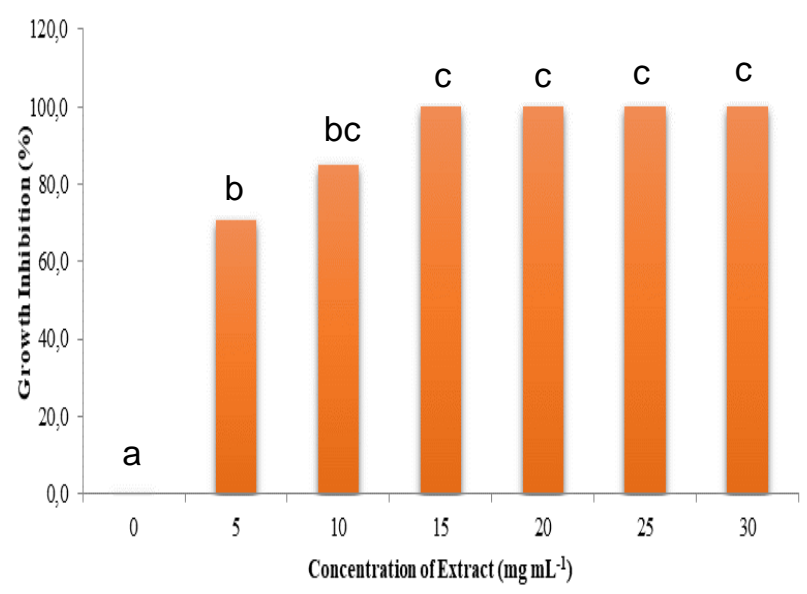

Figure 3 Growth inhibition of kebar grass stem ethanol extract on Aspergillus flavus BIO 2236 in peanut basedmedium (Values are mean $(n=3) \pm$ SE. The means followed by same letter are not significantly different according to ANOVA and Duncan's Multiple Range Tests)

Based on Table 2, compoounds such as Pyrocatechol, Guaiacol, and 2,6-Dimethoxyphenol was known can act as an antioxidant, as well as antimicrobial $[22,23]$. These compounds can be lethal for fungus cells or inhibit the production of metabolites such as mycotoxins [29]. From previous studies, it has been proven that eugenol $(0.68 \%)$, minor compound of kebar grass stem ethanol extract may be the main role in its antifungal activities. Other researcher [30], have indicated that the antimicrobial compounds of plant extracts can crosses the cell membrane and interacting with enzymes and proteins of the membrane. This interaction causes protons to flow outside the cell thereby inducing changes in the cell and triggering cell death. In addition, eugenol has also been reported as a compound with strong antioxidant activity that can increase the shelf life of food products by controlling the formation of free radicals and oxidation of unsaturated lipids.

Phenolic, terpenoids, including monoterpenes, sesquiterpenes, and oxygenated derivatives are chemical compounds that are often found in plant extracts. The other compound such as terpenes are 
also antimicrobial compounds that were often found in plant extracts or essential oils. The mode of action of this class of compounds is not yet fully understood, but it is thought that these lipophilic compounds involved to disrupt the cell membrane [31]. However, it seems that the antimicrobial or antifungal effect of plant extracts might be caused by the synergistic effect between other compounds [33]. Chemical compounds of plant extracts with low molecular weight and highly lipophilic easily crosses through cell membranes and induce biological responses [32]. However, most of plant extracts that have strong antifungal activity may be were resulted of the synergists of minor compounds with the major compounds. For example, terpene alcohols such as 1-limonene $(0.35 \%)$ has proven shows strong antimicrobial activity, while hydrocarbon derivatives have lower antifungal activities. This is due to the low water solubility which limits its distribution through the medium [34]. The presence of phenolic compounds in kebar grass stem ethanol extract can act as poison for microbes by inhibiting the enzyme activity, binds to sulfhydryl groups and proteins.

\subsection{CONCLUSION}

The result was conclude that kebar grass stem ethanol extract at concentration of $15 \mathrm{mg} \mathrm{ml}^{-1}$ in corn based-medium and peanut based-medium caused $100 \%$ growth inhibition of $A$. flavus. The major compounds in kebar grass stem ethanol extract were: Pyrocatechol, Methylhydrazine hydrochloride, 2-Fluoropropane, Isobutyric acid, 2,6Dimethoxyphenol. The use of natural plant extract provides an opportunity to avoid synthetic chemical preservatives and offers novel approach to the management of storage fungi. It was a promising method for preserving stored products in rural areas, which do not have access to modern storage system. Although characterization of the chemical composition and MIC value of the extract has been carried out, but to ensure kebar grass stem extract as a plant based antimicrobial, several parameters such as the application dosage and the cost-benefit ratio still need to be studied.

\section{Acknowledgement}

The authors would like to acknowledge the Directorate for Research and Community Service, Directorate General of Higher Education, Ministry of Education Republic of Indonesia for funding through Competitive Research Grants Hibah Bersaing 2013.

\section{References}

[1] Marin, S., V. Homedes, V. Sanchis, A. J. Ramos, and N. Magan. 1999. Impact of Fusarium moniliforme and $F$. proliferatum Colonisation of Maize on Calorific Losses and Fumonisin Production Under Different Environmental Conditions. Journal of Stored Product Research. 35: 15-26.

[2] Janardhana, G. R., K. A. Raveesha, and H. S. Shetty. 1998. Modified Atmosphere Storage to Prevent Mould-induced Nutritional Loss in Maize. Journal of Science, Food and Agriculture. 76: 573-578.

[3] Galvano F, A. Piva, A. Ritieni, and G. Galvano. 2011. Dietary Strategies to Counteract the Effect of Mycotoxins: A Review. Journal of Food Protection. 64: 120-131.

[4] Zain, M. E. 2011. Impact of Mycotoxins on Humans and Animals. Journal of Saudi Chemistry Society. 15: 129-144.

[5] Skoĉibuŝić, M., N. Bezić, and V. Dunkić. 2006. Phytochemical Composition and Antimicrobial Activities of the Essential Oils from Satureja subspicata Vis. Growing in Croatia. Food Chemistry. 96: 20-28.

[6] Özçelik, B., M. Aslan, I. Orhan, and T. Karaoglu. 2005. Antibacterial, Antifungal, and Antiviral Activities of the Lipophylic Extracts of Pistacia vera. Microbiological Research. 160: 159-164.

[7] Santoso, B., A. Kilmaskossu, and P. Sambodo. 2007. Effects of Saponin from Biophytum petersianum Klotzsch on Ruminal Fermentation, Microbial Protein Synthesis and Nitrogen Utilization in Goats. Animal Feed Science and Technology. 137: 58-68.

[8] Inngjerdingen M, K. T. Inngjerdingen, T. R. Patel, S. Allen, X. Chen, B. Rolstad, G. A. Morris, S. E. Harding, T. E. Michaelsen, D. Diallo, and B. S. Paulsen. 2008. Pectic Polysaccharides from Biophytum petersianum Klotzsch, and Their Activation of Macrophages and Dendritic Cells. Glycobiology. 12: 1074-1084.

[9] Lisangan, M. M., R. Syarief, W. P. Rahayu, and O. S. Dharmaputra. 2014. Antifungal Activity of Kebar Grass Leaf Extracts on the Growth of Aflatoxigenic Aspergillus flavus in Food Model Media. International Journal of Science: Basic and Applied Research. 17: 116-128.

[10] Sa'nchez, E., N. Heredia, S. Garc. 2005. Inhibition of Growth and Mycotoxin Production of Aspergillus flavus and Aspergillus parasiticus by Extracts of Agave Species. International Journal of Food Microbiology. 98:271-279.

[11] Abbas, H. K., R. D. Cartwright, W. Xie, and W. T. Shier. 2006. Aflatoxin and Fumonisin Contamination of Corn (maize, Zea mays) Hybrids in Arkansas. Crop Protection. 25: 1-9.

[12] Murugan, K., K. Anandaraj, and S. Al-Sohaibani. 2013. Antiaflatoxigenic Food Additive Potential of Murraya koenigii: An in Vitro and Molecular Interaction Study. Food Research International. 52: 8-16.

[13] Kumar, V, M. S. Basu, and T. P. Rajendran. 2008. A Review: Mycotoxin Research and Mycoflora in Some Commercially Important Agricultural Commodities. Crop Protection. 27: 891-905.

[14] Deng, Y., Y. YU, H. Luo, M. Zhang, X. Qin and L. Li. 2011. Antimicrobial Activity of Extract and Two Alkaloids from Traditional Chinese Medicinal Plant Stephania dielsiana. Food Chemistry. 124: 1556-1560.

[15] Joseph, G. S., G. K. Jayaprakasha, A. T. Selvi, B. S. Jena, and K. K. Sakariah. 2005. Antiaflatoxigenic and Antioxidant Activities of Garcinia Extracts. International Journal of Food Microbiology. 101: 153-160.

[16] Harborne, J. B. 1984. Phytochemicals Methods: A Guide to Modern Technique of Plant Analysis. $3^{\text {rd }}$ ed. London: Chapman and Hall Ltd.

[17] Valdés, F., L. Catalá, M.R. Hernández, J. C. GarcíaQuesada, and A. Marcilla. 2013. Thermogravimetry and Py-GC/MS Techniques as Fast Qualitative Methods for Comparing the Biochemical Composition of Nannochloropsis oculata Samples Obtained Under Different Culture Conditions. Bioresource Technology. 131: 86-93.

[18] Tian, J., X. Ban, H. Zeng, J. He, B. Huang, and Y. Wang. 2011. Chemical Composition and Antifungal Activity of Essential Oil from Cicutavirosa L. var. latisecta Celak. International Journal of Food Microbiology. 145: 464-470. 
[19] Manso, S., F. Cacho-Nerin, R. Becerril, and C. Nerín. 2013. Combined Analytical and Microbiological Tools to Study the Effect on Aspergillus flavus of Cinnamon Essential Oil Contained in Food Packaging. Food Control. 30: 370-378.

[20] Houghton, P. J and A. Raman. 1998. Laboratory Handbook for the Fractionation of Natural Extracts. London: Chapman and Hall.

[21] Sghaier, M. B., W. Bhouria, I. Bouhlela, I. Skandrania, J. Boubakera, L. Chekir-Ghediraa, and K. Ghediraa. 2011. Inhibitory Effect of Teucrium ramosissimum Extracts on Aflatoxin B1, benzo(a)pyrene, 4-nitro-o-phenylenediamine and Sodium Azide Induced mutagenicity: Corelation with Antioxidant Activity. South African Journal of Botany. 77: 730-740.

[22] Jaberian, H., K. Piri, and J. Nazari. 2013. Phytochemical Composition and in vitro Antimicrobial and Antioxidant Activities of Some Medicinal Plants. Food Chemistry 136: 237-244.

[23] Sousa, E. O., J. B. T. Rocha, L. M. Barros, A. R. C. Barros, and J. G. M. Costa. 2013. Phytochemical Characterization and in Vitro Antioxidant Properties of Lantana camara L. and Lantana montevidensis Briq. Industrial Crops and Products. 43: 517-522

[24] Skočibušić M, Bezić N, Dunkić V. 2006. Phyłochemical Composition and Antimicrobial Activities of the Essential Oils from Satureja subspicata Vis. Growing in Croatia. Food Chemsitry. 96: 20-28.

[25] de Lau, L. M. L., Bornebroek, M., Witteman, J. C. M. Hofman, A., Koudstaal, P. J. and Breteler, M. M. B. 2005 Dietary Fatty Acids and the Risk of Parkinson Disease. Neurology. 64: 2040-2045

[26] Lisangan, M. M., R. Syarief, W. P. Rahayu, and O. S. Dharmaputra. 2015. Aktivitas Antiaflatoksin B1 Ekstrak Daun Rumput Kebar (Biophytum petersianum) Terhadap Aspergillus flavus. Agritech. 35: 9-17.
[27] Diener, U. L., and N. D. Davis. 1969. Aflatoxin Formation by Aspergillus flavus. In: Goldblatt, L.A. (ed.). Aflatoxin: Scientific Background, Control, and Implications. New York: Academic Press. 13-39.

[28] Cuero, R., Smith, J. F., Lacey, J. 1988. Mycotoxin Formation by Aspergillus flavus and Fusarium graminearum in Irradiated Maize Grains in the Presence of Other Fungi. $J$ Food Prot. 51: 452-456.

[29] Malo-Vigil, A. L., E. Palou, and S. M. Alzamora. 2005. Naturally Occurring Compounds-Plants Sources. Davidson, P. M., Sofos, J. N., Branen, A. L. Antimicrobials in Food. 3rd ed. Boca Raton: CRC Press.

[30] Omidbeygi, M., M. Barzegar, Z. Hamidi, and H. Naghdibadi. 2007. Antifungal Activity of Thyme, Summer Savory and Clove Essential Oils Against Aspergillus flavus in Liquid Medium and Tomato Paste. Food Control. 18: 15181523.

[31] Cowan, M. M. 1999. Plant Products as Antimicrobial Agents. Clinical Microbiology Review. 12: 564-582.

[32] Bajpai, V. K., S. Shukla, and S. C. Kang. 2008. Chemica Composition and Antifungal Activity of Essential Oil and Various Extract of Silene armeria L. Bioresource Technology. 99: 8903-8908.

[33] Chao, L. K., K. F. Hua, H. Y. Hsu, S. S. Cheng, J. Y. Liu, and S. T. Chang. 2005. Study on the Antiinflammatory Activity of Essential Oil from Leaves of Cinnamomum osmophloeum. Journal of Agriculture and Food Chemistry. 53: 7274-7278.

[34] Prakash, B., P. Singh, A. Kedia, and N. K. Dubey. 2012. Assessment of Some Essential Oils as Food Preservatives Based on Antifungal, Antiaflatoxin, Antioxidant Activities and in Vivo Efficacy in Food System. Food Research International. 49: 201-208. 